\title{
Indigenous climate knowledge in southern Uganda: the multiple components of a dynamic regional system
}

\author{
Ben Orlove • Carla Roncoli • Merit Kabugo • \\ Abushen Majugu
}

Received: 19 November 2007 / Accepted: 29 October 2008 / Published online: 23 April 2009

(C) The Author(s) 2009. This article is published with open access at Springerlink.com

\begin{abstract}
Farmers in southern Uganda seek information to anticipate the interannual variability in the timing and amount of precipitation, a matter of great importance to them since they rely on rain-fed agriculture for food supplies and income. The four major components of their knowledge system are: (1) longstanding familiarity with the seasonal patterns of precipitation and temperature, (2) a set of local traditional climate indicators, (3) observation of meteorological events, (4) information about the progress of the seasons elsewhere in the region. We examine these components and show the connections among them. We discuss the social contexts in which this information is perceived, evaluated, discussed and applied, and we consider the cultural frameworks that support the use of this information. This system of indigenous knowledge leads farmers to participate as agents as well as consumers in programs that use modern climate science to plan for and adapt to climate variability and climate change.
\end{abstract}

\section{Introduction}

The principal goals of this article are to analyze a system of indigenous knowledge about climate, to document this system's complexity, large spatial, temporal and

\footnotetext{
B. Orlove $(\varangle)$

Department of Environmental Science and Policy, University of California,

Davis, CA 95616, USA

e-mail: bsorlove@ucdavis.edu

C. Roncoli

University of Georgia, Athens, GA, USA

M. Kabugo

Makerere University, Kampala, Uganda

A. Majugu

Department of Meteorology, Kampala, Uganda
} 
social scales, and dynamic nature, and to discuss the complementarities between this system and modern science. In addition, this article contributes to the extension of the large body of work on indigenous knowledge into the area of climate.

Interest in the topic of indigenous knowledge began several decades ago with the study of ethnoscience and taxonomy (Berlin et al. 1974; Hunn 1982; Atran 1985; Posey 1984, 1986). It then expanded into many areas of agricultural development and natural resource management (Brokensha et al. 1980; Ashby 1985; McCorkle 1989; DeWalt 1994; Thompson and Scoones 1994; Rhoades and Bebbington 1995; Warren et al. 1995; Chambers 1996; Richards 1993; Nazarea 1999, 2006; Cleveland and Soleri 2007). Recent studies document the effectiveness of indigenous knowledge in land management in a number of settings (Brodt 2001; Verlinden et al. 2006) and show that indigenous knowledge persists even in contexts of commercial land use and government land management (McDaniel et al. 2005).

The term "indigenous knowledge" is well-established in the literature, even though other terms, such as local, traditional, vernacular, or folk knowledge, are also used (Ellen and Harris 2000; Antweiler 2004). Here, we use the term to refer to the place-based knowledge that is rooted in local cultures and generally associated with long-settled communities which have strong ties to their natural environments. Such knowledge tends to be the result of cumulative experience and observation, tested in the context of everyday life, and devolved by oral communication and repetitive engagement rather than through formal instruction (Ingold 2003; Sillitoe 2006, 2007). While it is often defined in contrast to scientific or Western knowledge, indigenous knowledge should not be seen as a rigid, static repertoire of traditions that is unable to incorporate innovations (Cleveland and Soleri 2007; Dove 2000). Rather, it is a flexible entity which, by virtue of its diverse and empirical nature, can easily integrate skills and insights from other knowledge systems as well as from experimental practice.

The broad appeal of indigenous knowledge to academic researchers and to organizations that support the dissemination, interpretation and use of applied science has led to the institutionalization of indigenous knowledge as a component of projects, programs and international agreements (Mauro and Hardison 2000). This broad appeal has also evoked strong concerns about the tensions between the different criteria and orientations of the academic and applied audiences for these findings (Agrawal 1995, 2002; Appadurai 1995; Antweiler 1998; Purcell 1998; Sillitoe 1998a, b, 2000; Brosius 1999; Dove et al. 2007).

There has been a great deal of research on indigenous knowledge in agriculture, forestry, biodiversity and soils, but much less has been carried out in the climate area (Waddell 1995; Sillitoe 1996; Vedwan 2006). This relative scarcity stems from several sources. Climate organizations usually operate at the national, regional and international levels, where indigenous knowledge is more difficult to incorporate, while projects in agriculture and natural resource management are often at a smaller scale, where it can be accessed more readily. A growing interest in intellectual property has led to an interest in areas of knowledge that, unlike climate knowledge, can be patented or protected, as the discussion of indigenous knowledge of traditional crop varieties and medicinal plants have shown (Thrupp 1989; Brush and Stabinski 1996, Posey 1996, 2000).

It is noteworthy that in climate as in other environmental domains, many populations around the world are close observers of the natural world. A recent review 
(Roncoli 2006) examines ethnographic research on indigenous climate knowledge that has been carried out to date in terms of its relevance for the application of scientific climate forecasts. Some studies look at the indicators that are used to forecast weather or seasonal variability (Pepin 1996; Huber and Pedersen 1998; Orlove et al. 2000, 2002). Others look at the integration of these indicators with agricultural practices (Osunade 1994; Roncoli et al. 2002) and show the potential of drawing on indigenous knowledge for programs involved in forecast dissemination (Kanani and Pastakia 1999; Roncoli et al. 2002; Kihupi et al. 2003; Roncoli 2006) and in programs to reduce vulnerability to droughts (Mutiso 1997). One interesting study (Cruikshank 2005) traces the interactions of glaciologists and First Nations in the Canadian Yukon to show how indigenous knowledge can provide information that scientists find useful for research.

\section{Context of research}

The research site, Rakai District in southwestern Uganda near the border with Tanzania, was selected based on several criteria, the main ones being its vulnerability to climate stress and the local predominance of agricultural livelihoods, to which climate forecasts can be applied more readily than they can to livestock-based systems. Because of its exposure to climate risk, Rakai is also one of the priority districts in the National Adaptation Programme of Action (NAPA), and the District Agricultural Office was particularly well disposed to assist by helping us contact farmers. In addition, we sought areas where Luganda (the language of the Baganda people, Uganda's largest ethnic group) was spoken as the prevalent language, since the research entailed linguistic analysis and our research team had expertise in that language. Within the district, which is diverse in terms of agro-ecological and climatic conditions and livelihood systems, we selected two sub-counties (units of local government) that best satisfied these criteria (Figs. 1, 2 and 3).

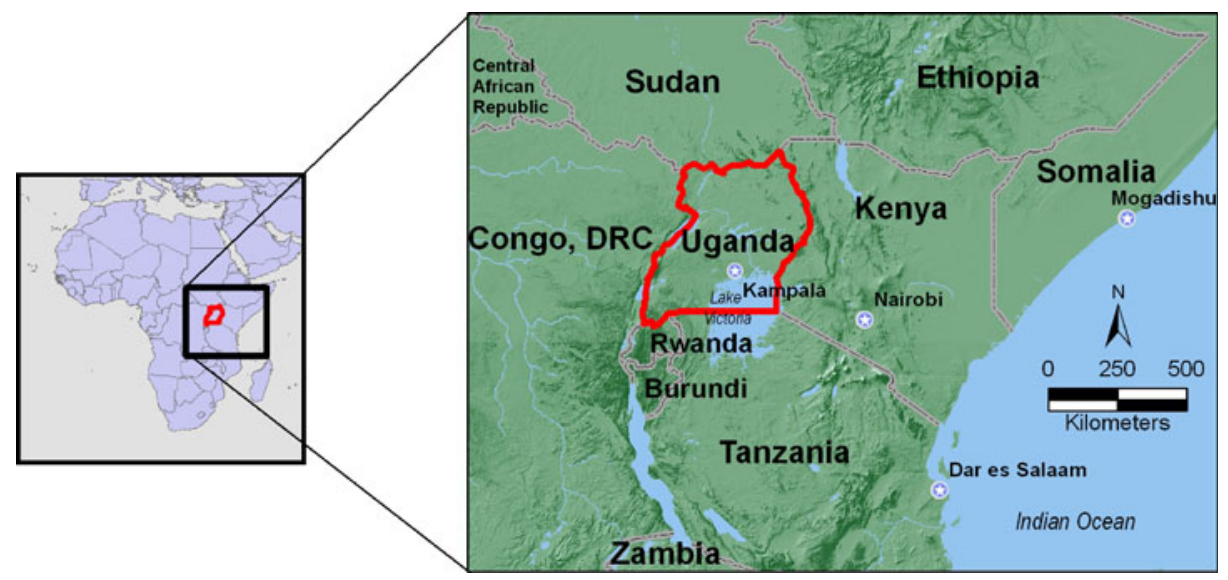

Fig. 1 Map of Africa, showing Uganda in East Africa 


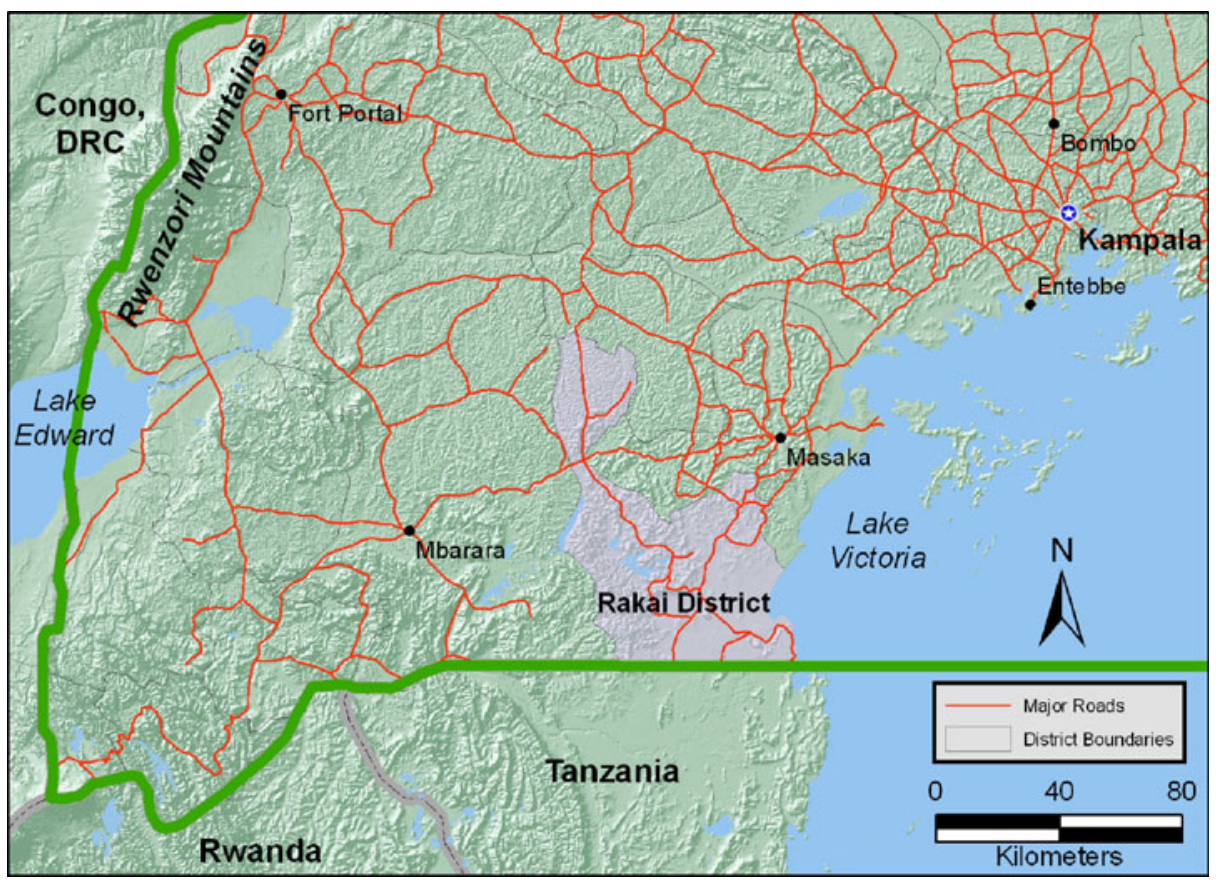

Fig. 2 Central, southern and western Uganda, showing Rakai district

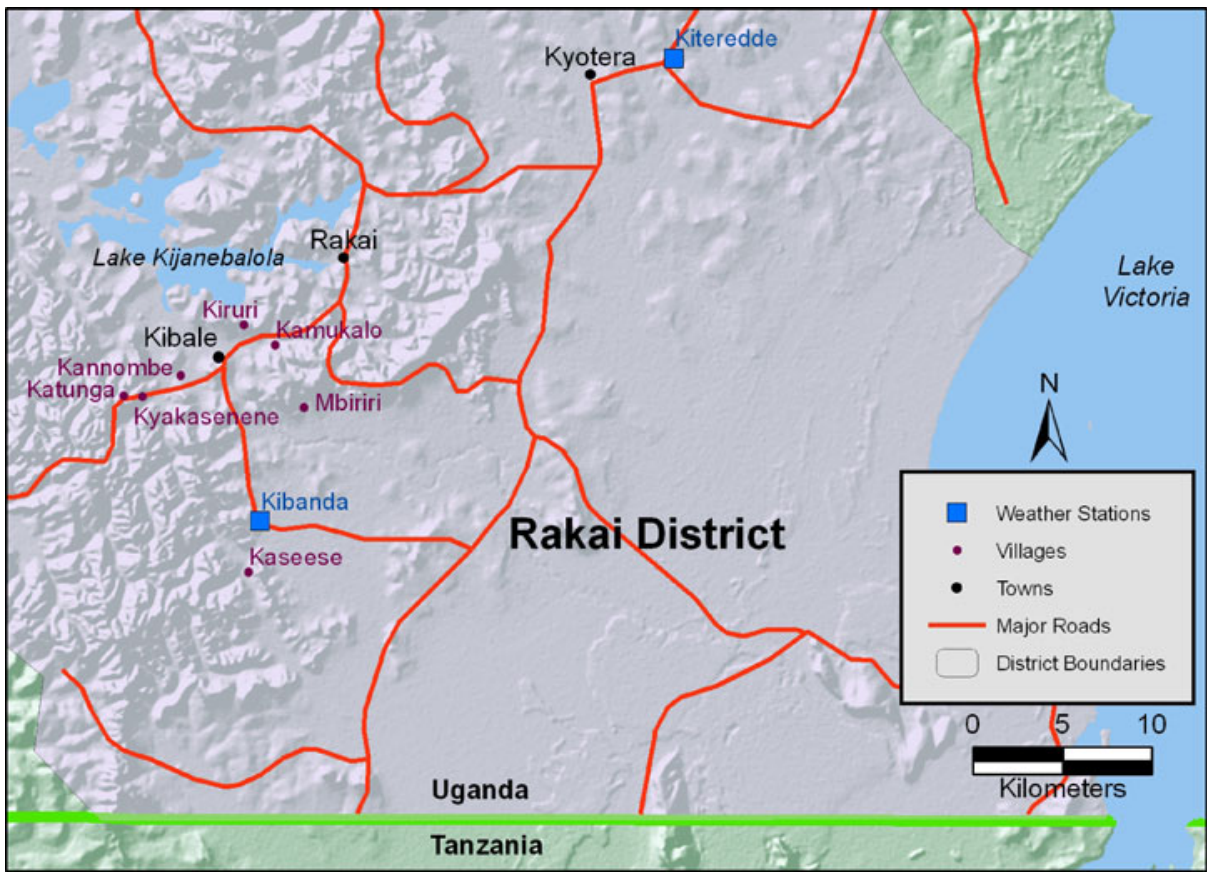

Fig. 3 Rakai district in Uganda 
The population of Rakai District is predominantly Christian, with Catholics, members of the Church of Uganda (closely associated with the Anglican Church), and some Pentecostal groups as the most numerous denominations, though there is a significant Muslim minority. The district's residents include members of several ethnic groups, a matter of significance for the study of indigenous knowledge. The district forms part of Buganda, the region of the Baganda people, and the majority of the inhabitants are Baganda. Buganda is one of several pre-colonial kingdoms that have continued their existence through British rule and into the era of Ugandan independence; though these kingdoms are ancient and draw extensively on African traditions, they may seem less closely associated with the term "indigenous" than other groups in Uganda, particularly small populations of forest hunter-gatherers and cultivators, such as the Batwa, formerly called by the pejorative term "pygmies," who inhabit the western lowland rainforests, and the Bakonjo of the upper slopes of the Rwenzori Mountains.

The district also include a significant number of Banyankole, an ethnic group whose homelands lie to the north and west; cattle-raising forms a more important part of the economy of the Banyankole than it does for the Baganda. In addition, the region is home to many Bakiga who have migrated from the densely settled mountains of southwestern Uganda, and to others who have moved from Rwanda and Burundi.

The Ugandan Department of Meteorology collects data at three stations, Kalisizo, Kiteredde and Kibanda, which are in or very close to our research area, and has provided monthly totals for the periods 1963-1976 and 1999-2005 (Majugu 2006). These data show that the average annual rainfall for the region is $1,039 \mathrm{~mm}$. The first rainy season, running from March to May, is shorter (3 months), but receives more rain, averaging $436 \mathrm{~mm}$ for the season. Rains are more intense and closely spaced. Both the onset and the end are abrupt. The second season, from September through December, is longer ( 4 months) but there is less rain, with a seasonal average of only $386 \mathrm{~mm}$. The rain events are more widely spaced, but fall more regularly and steadily, so they are better for soil infiltration and crop growth. The onset and end are less well defined, and sometimes rains continue into January. The dry period that runs through June, July and August is longer than the one in January and February; the average monthly rainfall during these dry seasons is $43 \mathrm{~mm}$, which is insufficient for agriculture. As in other parts of East Africa (Anyah and Semazzi 2006), there is significant variability in the timing and amount of rainfall in both seasons. In recent years, meteorologists have improved their ability to forecast this variability, drawing on historical analogies and on regional models that include ENSO indices, Indian Ocean sea surface temperatures, conditions in the Congo Basin and the Arabian Peninsula, and other factors. The Ugandan Department of Meteorology, often collaborating with the meteorological services of other East African nations, prepares seasonal forecasts for different regions of the country, each of which includes several districts. They disseminate these forecasts through the government media advisories and agricultural extension services. Local FM radio stations, broadcasting in Luganda and other African languages, also spread these forecasts.

The seasonal distribution of rainfall has implications for local knowledge, because it is so important for agriculture and for domestic water supply. People are eager to determine when rains are going to start during the first season (because it is shorter and they need to plant as early as possible) and during the second season (because they are unsure if a rain in late August or early September means that the rainy 
season has started). Seasonal rainfall variability influences family well-being as well as agricultural production. If a season brings very little rain, people have to travel farther to fetch water from streams, ponds, and wells, a considerable burden that falls almost exclusively on women and children, who are also responsible for a large amount of agricultural labor. Yet farmers make fewer references to water supply than to agriculture in their discussions of forecasts and of upcoming rainy seasons, perhaps because there are very few preparations that they can take to address a possible scarcity of water. Even these steps-repairing a bicycle so it can be used to carry jerry-cans of water, or purchasing an additional water basin-do not need to be made in advance, but can be carried out when the scarcity presents itself.

Men and women both cultivate fields ("gardens") around the homestead, with women growing primarily for home consumption and men placing greater emphasis on sale at the market. This region is marked by a diversity of crops (Mukiibi 2001). This variety allows farmers to diversify agronomic and market risks, to make use of different types of soil and to accommodate climate variability; in addition, it satisfies their strong cultural preference for serving several starchy staples, rather than just one, at meals. Bananas (Musa sp), the main staple food for the Baganda, are grown on the lower slopes and in the moist valley floors between the ridges of hills. A perennial crop, bananas are often intercropped with beans and constantly replanted so that each grove comprises plants at various stages of growth, providing a regular supply of food. Annual crops are planted during each rainy season, according to the crop's growth cycle and water requirements and to farmers' expectations for the unfolding of the rains. Some annual crops, such as maize (Zea mays L.), beans (Phaseolus vulgaris L.), and peanuts (Arachis hypogea L.) can be either eaten or sold, while potatoes (Solanum tuberosum $\mathrm{sp}$ ) and sweet potatoes (Ipomea batatas L.) are mostly sold. Cassava (Manihot esculenta) is grown by most households as a "hunger" crop, to be eaten when annual crops are not yet harvested. It is mostly planted in October so that it is well established during the June-August dry period, but farmers may plant it during the first season if they expect the rains to be abundant and last into June. Pastoralists and immigrants also cultivate sorghum (Sorghum bicolor L.) and finger millet (Eleusine coracana L.) which they prefer to banana as a staple, while the majority of Baganda farmers do not like to produce or eat these grains. Households also raise poultry, pigs, goats, and cattle or maintain coffee groves for cash income.

Predictions about the timing of the onset of the rains are particularly important, because some longer cycle crops, such as potatoes and maize, are often planted in dry soil in anticipation of the rains. Some farmers report that this practice is becoming less common as they are losing confidence in the reliability of the rains and in their ability to predict them. They choose not to plant these longer cycle crops during the shorter March-May season, particularly if the rains have not started by late March, as was the case in 2006. Beans are sometimes planted before the rains in new fields or in banana gardens, both of which retain moisture during the dry period, but they are usually planted after it starts raining. Peanuts and sweet potatoes, which need good soil moisture, are planted later in the season, when the rains become more frequent. During the March-May season, farmers may decide not to plant them if they fear that the rains may be poor or end early.

In choosing what and when to plant, farmers must contend with several constraints. Labor is often scarce. The AIDS epidemic has severely impacted rural 
communities, depriving them of many able-bodied members and leaving households composed of elderly people, women, and children. In some cases land availability is a constraint as well. Although soils are relatively fertile, soil erosion is a problem in some areas, due to deforestation and periodic burning of the hilltops and slopes by pastoralists. Arable land is scarce in some communities, particularly where narrow valleys are hemmed in by steep hills and where wealthy livestock owners from other areas have leased much of the available land, including agriculturally valuable valley bottoms. This scarcity limits farmers' ability to expand their fields and to exploit different agro-ecological niches in response to rainfall predictions. Timely planting (if farmers expect poor rains) or field expansion (in case of good rains) can also be hindered by the high cost of seed, as cash is particularly scarce at the onset of the season when many households are forced to buy food. Lack of money is a chronic problem, since farming communities are far from market centers and roads are very poor, so that farmers are at the mercy of middlemen who come to the farm gate and offer low prices for their crops. At times of illness or hunger, rural households are vulnerable to predatory lending.

In sum, farmers have important decisions to make in each season about the crops that they select and the area and timing of planting. A small fraction of the farmers simply wait for the rains to have advanced far enough for the ground to become moist, and only then do they plant. However, advanced knowledge, whether from indigenous or scientific sources, is of great value to the farmers. It allows them to include slower-maturing crops that would be excluded if they waited until the rains had settled in, and it also permits them to decide whether to clear, cultivate and plant a larger area than usual. They thus seek this knowledge avidly, both from indigenous sources and from the climate forecasts that the Ugandan Department of Meteorology prepares.

In addition to its economic importance, rain has a cultural and religious significance in Rakai District as in other parts of Uganda. Scanty rains can be taken as the sign that God and the spirits of the ancestors are displeased with local people because of their conduct; in contrast, abundant rains can indicate divine or cosmological favor. For example, couples who marry are pleased when rain falls on the day of their wedding, since it bodes well for a future of prosperity and numerous healthy children. Even when people gather to bury a relative in the home village, the arrival of rains is considered a positive sign, since it means that the deceased was a person of good character and that the spirit world is pleased with the good works that the person carried out in life. The relief that accompanies the first rains of an agricultural season rests in part on the expectation of good harvests, but it includes an additional component of reassurance that the world is in good order, much as the distress that comes when rains are delayed stems not only from a fear of hunger, but also from concerns that the social and religious realms are not quite right.

\section{Methodology}

Fieldwork spanned over 18 months, with 4-6 week visits in March-April 2005, August-September 2005, March-April 2006, and September-October 2006. These visits were scheduled to coincide with the onset of the first and the second rainy seasons of 2005 and 2006, which enabled us to explore the farmers' own predictions 
concerning the nature of the upcoming rainy season and their planting decisions during the first crucial weeks of the season. As is often the case with research on climate variability, our work was affected by the specific nature of the seasons during the time of our research; the late onset of the rain in the seasons starting in September 2005 and in March 2006 was a great concern for the farmers in the region, and may have influenced the ways that they thought and spoke about climate.

The research design combined semi-structured and informal methods of data collection, including individual and focus group interviews with farmers, interviews with government employees, NGO staff and small business owners, recordings of farmer group discussions, and participant observation. Interviews and group discussions elicited information on farmers' expectations for the upcoming season, local forecasting knowledge, access to scientific forecasts and technical advice, and planting decisions for the previous and current season. Several open-ended interviews with district officials, community leaders, agricultural technicians, NGO field agents, and other resource persons were also conducted to obtain additional information on risk management in agricultural strategies.

In this paper we use all of these for contextual information, and we draw extensively from two sets of interviews with individual farmers conducted in September 2005 (17 men and nine women) and in September 2006 (12 men and 25 women). Respondents were selected purposively rather than randomly because of the difficulty of traveling to distant homesteads on poor roads and the challenges of mobilizing farmers at the onset of the rainy season, when they were busy planting their fields. Farmers were contacted through the extension service and through an NGO agent; some of them belonged to farmers' groups that intervened in agriculture, AIDS prevention, and community development, while others did not belong to such groups. These groups are very active in this region, and well over half the farmers participate in at least one group. Efforts were made to include farmers from different sectors and wealth strata. Interviews were mostly conducted in the respondents' home or fields, which enabled us to make a preliminary assessment of their socioeconomic conditions. For linguistic reasons, the majority of respondents were native speakers of Luganda. Interviews were conducted in this language, with Ugandan team members translating between English and Luganda.

In addition to individual interviews, we conducted 8 focus groups in different villages of the district. They were comprised of members of farmers' groups and of other villagers who gathered spontaneously in outdoor settings to meet with the research team. The groups ranged in size from five to 20 , and included a total of 48 men and 47 women. Group size and composition fluctuated a great deal as people moved in and out or stood by at a short distance. The groups were primarily composed of Baganda farmers, although some included pastoralists from the neighboring Banyankole ethnic group and immigrants from several other ethnic groups. Some focus groups consisted of established farmers' groups, and others, of villagers who gathered spontaneously in an outdoor venue to meet with the visiting team. In these settings, local forecasting knowledge was often brought up spontaneously when discussing the subject of climate variability. In some cases, people readily enumerated a wide repertoire of indicators.

Finally, we also derive information from 15 meetings with farmer groups held in September 2005 and in March 2006. The groups ranged in size from five to 34 participants, including 130 women and 78 men, as well as a large number of children, who often lingered to observe the activities of the group. During these meetings, the 
farmers were presented with a Luganda version of the scientific climate forecast for the upcoming rainy season produced by the Ugandan Department of Meteorology. Participants then proceeded to discuss among themselves how they understood and how they may use the information (no instructions were given as to how or what they should discuss). During these discussions, participants pondered the forecast that they had just received and compared it with their own experiences and expectations of how the season would progress. They also considered whether and on what basis the information seemed credible, and how they might use it in their farming decisions. Farmers also made references to and asked questions about climate change and what they could do to mitigate its impacts, and many of them offered suggestions to the Department of Meteorology to improve the forecasts. These discussions were recorded, after obtaining permission. They were subsequently transcribed in Luganda, translated into English, coded and analyzed.

During part of the fieldwork we resided in the village of Kibale, which is the venue of a periodic market that serves the two sub-counties where we worked. During this time we also visited farmers' homes and fields, participated in meetings of farmers' groups, and attended local markets, church services, and other community events. We were hosted by a local family, who owned a popular inexpensive restaurant where people often assembled in the afternoon for a meal, a drink, or to watch television. This setting provided an opportunity to observe local interactions and witness spontaneous remarks people made about the upcoming rains. These commentaries had a particular salience and urgency when people were worried about a delayed onset of the rains or a prolonged dry spell.

\section{The multiple components of indigenous climate knowledge}

We use two terms to describe the central features of indigenous knowledge. The more general term is component, which describes a source or basis for knowledgesuch as familiarity with historical climate patterns, awareness of signs that have cultural significance, observation of meteorological events as they occur, and information about weather elsewhere in the region. Though generally distinct, there are a few cases of overlap between these components; for example, wind patterns share some characteristics of both weather observations and culturally significant signs. The more specific term is element, the particular instances that comprise each of these components or the specific kinds of indicators that are observed. For example, comments about the shape or color of clouds are elements of the component defined as "observations of meteorological events".

\subsection{Historical climate patterns}

The people of Rakai, most of them long-settled in their territory, have a collective memory of weather patterns that extends into the past. This understanding of the historical pattern of seasons establishes the basic framework against which variability and change are observed. They share a strong sense of the climatology, or characteristics of the seasons. Local people give different names to the two rainy seasons, and are familiar with a number of attributes. They know the typical timing 
and duration of the seasons. The first rainy season (toggo in Luganda) is expected to run from March through May; the second season (ddumbi in Luganda) runs from September through December. Though they do not describe amounts in millimeters of precipitation, farmers distinguish the quantity of rain that has fallen during each season. By scraping soil away with their hands, or digging with hoes, they examine soil moisture after the onset of the rains to determine when enough has fallen for viable planting. A number of people mention a belief in the occurrence of a specific sequencing of seasons, according to which if one season is unfavorable, because of its scanty or irregular rains or of its short duration, then the next season will be better.

Farmers pay particular attention to the variation in the timing of dry spells and in the onset and end of the rains. Prolonged dry spells can cause significant crop damage: farmers note that these occur more often in the second season than in the first and that they have become more frequent overall. Farmers often comment that the timing of the onset of the rains has become less regular. Though the meteorological data for the stations in this region do not support this point strongly, the collective memory of the farmers in the district stretches back at least to the early decades of the last century, well before the beginning of data collection at the nearby meteorological stations in the 1960s and at stations elsewhere in southwestern Uganda in the 1940s, so their comments may thus have some validity.

The knowledge of climatology extends beyond the immediate confines of village communities to extend to neighboring districts, including those of other language groups, as far as $150 \mathrm{~km}$ away. On a coarse mesoscale, farmers in Rakai district know that there are moister regions both to the east, along the shores of Lake Victoria, and to the west, in the mountains that rise up to the Rwenzoris. They are aware as well of drier regions to the immediate northwest, which is the territory of the Banyankole. This area lies in the rain shadow of the Rwenzoris: its lower precipitation makes agriculture risky, so pastoralism prevails in those areas. The farmers are familiar with the timing as well as the amount of rain in different regions, and know that the rainy season generally arrives a few weeks earlier in the west, and spreads eastward. On a finer microscale, Rakai farmers note that some villages tend to receive more rain than others, particularly where the rainstorms coming from Lake Victoria are not blocked by hills. This knowledge of the characteristic temporal and spatial patterning of rainfall focuses people's attention during the weeks preceding the expected onset of the rainy season. It directs them to seek out clues that may give them a sense of when the rains will start. To this end, they draw on the three other components of indigenous knowledge.

\subsection{Signs}

Another component, broadly similar to indigenous knowledge in other areas of the world, is a set of indicators of the onset of rains. The Luganda term for these indicators, obubonero, translates readily into the English word "signs". These are widely-known signs that foretell events, including not only rain but also many other events unconnected with climate and weather, such as illness, good fortune and the arrival of a visitor. The connection between a sign and the event it foretells tends to be symbolic, rather than material or causal; thus, the appearance of a swarm of red ants in a courtyard is a sign that a member of the family will die within a 
week, and a peeled plantain that stands up in a cooking pot, rather than lying in the usual horizontal position, is a sign that a guest will arrive unexpectedly at the next meal. These signs are taken to be generally reliable, but they are not considered deterministic.

A number of signs, often mentioned in the interviews, in the group meetings, and in conversations, indicate that the rains will start within a few weeks. These include an increase in nighttime temperatures, so that the nights feel uncomfortably warm (many people speak of hot nights, reporting that they feel sweaty and wish to bathe when they wake in the morning); shifts in the direction of prevailing winds; the flowering of trees, especially coffee trees; particular phases of the moon; the appearance of whirlwinds that lift dust and leaves; and the arrival of migratory birds, particularly the Abyssinian hornbill (Bucorvus abyssinicus). This bird's call is said to resemble the Luganda word ggulu, which means "heaven", and to connote the phrase ggulu mpa enkuba or "Heaven, send rain." The whirlwinds also have a symbolic interpretation: their Luganda name is akazimu, literally "ghost-wind," and they are understood to be a manifestation of the ancestor spirits that are active just before the rains, sometimes fighting among themselves.

Individuals who see any of these signs are likely to mention them to their relatives, neighbors and friends. Thus, someone who greets a neighbor in the morning might comment on how unpleasantly warm the previous night had been. In general, people agree on the meaning of these obubonero, though there can be some disagreement in the details. For example, among indicators that the rains are about to start, some people look for a change in wind direction from easterlies to westerlies, while others look for a shift from southerlies to northerlies. It is generally believed that rain is more likely during the dark phase of the moon, but during a meeting of a farmers' group, two people overtly disagreed on whether it was during the waning or waxing phase that rain was more likely to start. These signs, though considered to be part of farmers' traditional knowledge, do reflect historical changes. For example, coffee cultivation in this part of Uganda was not common until the 1940s, and so the habit of observing the flowering of the coffee tree as a sign for the onset of the rain must have developed after this time.

The question of accuracy often arises in discussions of indigenous knowledge, particularly in cases of relatively arbitrary or symbolic signs such as these. Though the weather stations in the region do not collect the data on overnight minimum temperatures and wind direction that would allow for direct empirical verification of these signs, several of them can plausibly be linked with the spread of the rains into Rakai. The arrival of the Intertropical Convergence Zone [ITCZ] from the south in March and its return from the north in September could be associated with shifting in prevailing winds. Increased convection over the Lake Victoria basin in the weeks before rains begin in Rakai is mainly during the night and early morning. This increased convection at the onset of the rainy season implies increased downward motion over Rakai, and the warming of air that accompanies downward movement and compression could be associated with unusually warm nights. These conditions could also be associated with small-scale variations in heating that would favor the development of vigorous whirlwinds. Research in other areas has linked shifts in the flowering patterns of trees to El Niño events (Curran et al. 1999) and shown that migratory birds often use the movements of fronts to provide them with tailwinds (Liechti 2006). 


\subsection{Weather observations}

Local people are also attentive to the visible and audible evidence of the immediate presence of rainstorms as they arrive in the area; these constitute the third component considered here. This evidence differs from the obubonero in several ways. Weather observations are linked physically rather than symbolically to rain; local people do not generally mention them when they are prompted for obubonero, and they think of this knowledge as something that is common sense and inferred from personal experience, rather than something that is learned from others, as signs are. Among the most commonly reported weather observations are the dark clouds that gather on the horizon or that mass in the sky. In addition, people observe lightning flashes over Lake Victoria $30 \mathrm{~km}$ to the east, the much smaller Lake Kijanebalola $15 \mathrm{~km}$ to the west or the foothills of Rwenzori Mountains $150 \mathrm{~km}$ to the northwest and over lower ridges nearby, and they hear the rumble of thunder. The lead time between these observations and the occurrence of rain can vary; distant lightning might suggest that rain could come in a week or two, while several days of heavy clouds would indicate a shorter interval before the onset of rain.

There is significant variation in the language that farmers use to discuss their weather observations. In the case of clouds, some simply refer to them as "black clouds," while others employ more figurative language. For example, a farmer stated, "In this area when rain comes we see thick huge clouds from the west around the evening. [They are] as big as hills." Another woman, describing her ability to anticipate the arrival of rains, said, "The clouds look mature, holding water. This shows that the rains are coming soon," while another referred to the arrival of "clouds [that] are still heavy, holding rain." On a few occasions, local farmers used the term "nimbus," and one added that these were "rain-bearing clouds." This term is taught to primary school students as part of the science curriculum, and reflects the openness to incorporating material from formal education and from science into their indigenous knowledge. This diversity of forms of description of clouds calls into question the usefulness of the tendencies in the study of indigenous knowledge to create checklists of unqualified indicators that may be either present or absent (Kihupi et al. 2003). Such approaches downplay the variety of ways that individuals can draw on the shared stock of knowledge, a variety that enriches the extensive conversations about weather and climate in this region.

\subsection{Regional information}

Information about weather conditions in other parts of southern and western Uganda, and across the border with Tanzania, complements the other sources of knowledge. People listen attentively to news about rain in other locations, and pass on such news to others. When people travel, they ask local residents about recent rain events, and look for evidence of rain, noting whether the soil is moist, or whether the leaves on trees along roads are dusty, or recently washed by rain. Unusual events attract the attention of travelers, who may then report their observations to others. In a particular instance during fieldwork, while we were traveling from one village to another in a van, one passenger looked through the window and noticed that the leaves of banana trees were torn in a way that indicated that hail-associated with heavy rainstorms and with lightning - had recently fallen. Before leaving the 
first village, several of them had noticed clouds in the direction in which we would be traveling so they had expected to find that rain had fallen, but they would not have known that the hail had fallen had they not noticed the banana leaves. Similarly, people listen to news on radio stations, particularly the local FM stations that broadcast to the immediate region in Luganda and in Runyakole, the language of the Banyankole; announcers and individuals who call in often mention rainstorms. The timing and location of rainstorms in nearby areas helps people anticipate the likelihood of the arrival of rain in their own villages. The lead time for this source can also vary; if rains are spread more widely over the region, or if they occur closer rather than farther, they can be expected to start sooner in the district.

\subsection{Distribution of the components of indigenous knowledge}

The interviews conducted with farmers in Rakai district shows the relative distribution of these components of indigenous knowledge. In discussing the current season with the farmers, we asked them whether they had expectations of how that season would go, and what the basis of their expectations was. We did not propose to them a list of possible sources (components), nor did we press them to develop their answers, but simply let them mention the indicators that came to their minds. In this way, we obtained figures for the rates of use of the different components of knowledge that do not overestimate the actual rates of use, since some people might mention only the most salient indicators, rather than all those they noted or used. The common use of seasonal terms in everyday conversation, for example, shows that virtually everyone is familiar with the local understanding of the seasons, even though our figures only count the $46 \%$ who specifically mentioned them. Similarly, the frequent mention of signs and weather observations in the group meetings suggests that these components are more widely used than the figures of $39 \%$ and $21 \%$ in the table below would indicate. In other words, these figures provide conservative estimates of the actual use of the components. We include the results of these interviews in Table 1.

Averaging across the entire population, including those who offered no sources for their expectations for the season and those who did not have any expectations, the individuals in our sample mentioned 1.32 components and 1.56 specific elements. Warm night temperatures and shifts in wind were the most commonly mentioned signs. Four signs (an unexpected loud noise from a hill; the appearance of white ants; the appearance of the new moon; a fog coming from ridges) were mentioned by only one individual, giving a total of $6 \%$ for "other" signs. A large majority, $89 \%$ of the total, had some expectations of the coming season, drawing on the observations made within their system of indigenous knowledge. Most of the people $(70 \%$ of the total) named at least one source of their expectations; the remaining 19\% did not state the source of their expectations (since individuals gave multiple replies, cumulative totals sometimes exceed $100 \%$ ). A minority of $11 \%$ stated that they had no expectations, and indicated that they would tend to wait for the rains to moisten the ground before planting. A sub-set of these, totaling 7\% or about two-thirds of those without expectations, spoke explicitly about God. As one woman explained, "The seed that I get, I put it in the ground [when the rains have moistened the soil] and then God knows what to do, but I do not know what God has planned for us". 
Table 1 References by individuals to components and elements of indigenous knowledge in farmer interviews $(N=63)$

\begin{tabular}{|c|c|c|c|}
\hline Component type & Specific element & $\begin{array}{l}\text { Percentage of } \\
\text { respondents } \\
\text { mentioning } \\
\text { component type }\end{array}$ & $\begin{array}{l}\text { Percentage of } \\
\text { respondents } \\
\text { mentioning } \\
\text { specific element }\end{array}$ \\
\hline \multirow[t]{3}{*}{ Historical patterns } & & 50 & \\
\hline & Details about normal seasons & & 46 \\
\hline & Beliefs about successive seasons & & 7 \\
\hline \multirow[t]{6}{*}{ Weather observations } & & 39 & \\
\hline & Clouds & & 21 \\
\hline & Sun & & 20 \\
\hline & Lightning & & 6 \\
\hline & Thunder & & 2 \\
\hline & Other & & 2 \\
\hline \multirow[t]{4}{*}{ Signs } & & 21 & \\
\hline & Wind & & 11 \\
\hline & Night temperatures & & 6 \\
\hline & Other & & 6 \\
\hline \multirow[t]{2}{*}{ Regional information } & & 9 & \\
\hline & Rain & & 9 \\
\hline \multirow[t]{2}{*}{ No previous knowledge } & & 11 & \\
\hline & Trust in God & & 7 \\
\hline
\end{tabular}

This matter of the farmers' empirical and religious beliefs merits a brief digression at this point (Hintjens 1997). Though most of the people who did not form expectations from indigenous knowledge mention God as the source of rain and indicate that God's actions cannot be known, the obverse does not hold: the people who did form expectations also understand God as a crucial force in the natural world, though, unlike the others, they rely on the indigenous knowledge system to provide them with useful information about the upcoming rains. As in many rural communities in Uganda, faith in God is widely shared, and all can name the specific Christian denomination or branch of Islam with which they are associated. Daily conversations and group discussions reflected a shared value for showing respect to God. Yet, there is no incompatibility between belief in God and a reliance on indigenous knowledge, in local people's views. Rather, they explained that God created an orderly world with regular patterns and signs for humans to observe.

In formulating expectations for weather and climate, people draw on different combinations of sources of knowledge. Many of the farmers interviewed mentioned only one component: $29 \%$ discussed historical patterns, $16 \%$ spoke of weather observations and $4 \%$ referred to signs. At least two components were mentioned by $21 \%$ of the farmers, with the most frequently mentioned combinations being weather observations and signs ( $9 \%)$ and historical patterns and signs (7\%).

There was some variation in the frequencies whereby components were mentioned in the focus groups. All the groups mentioned historical patterns of seasons, and 6 of the groups mentioned the signs, with an average of just over 4 signs per groups. There was only partial overlap in the mention of specific signs between the focus groups and interviews. Both frequently mentioned shifts in the wind, and spoke as well, though less often, of hot nights. However, flowering trees, mentioned 
by many groups, did not appear in the interviews, while some signs mentioned in an interview-white ants, fog on ridges - did not come up in the groups. Only one group mentioned the weather observations, speaking of clouds and thunder, and none discussed regional information. This difference may reflect the distinct social dynamics of the interviews and the focus groups. Focus groups tend to yield normative, generalizable responses, while interviews are better able to convey actual strategies that individuals and households employ.

\section{Characteristics of indigenous climate knowledge}

Based on the research findings presented above, we identify a number of characteristics of climate-related indigenous knowledge used by farmers in Rakai district in anticipating the rains.

\subsection{Social nature of knowledge}

These examples have indicated the highly social nature of the knowledge. Although most agricultural tasks are carried out by individuals, rather than larger social groups, and most climate information, such as the signs and the weather observations, is collected by individuals, people discuss information with others. They exchange information to which they might not otherwise have access, helping them gain a firmer sense of the arrival and progress of the rains. Moreover, all the components of this knowledge- the historical patterns, the signs, the weather observations and the regional information-are widely accessible and widely shared. Elders are treated with respect in conversations about weather as in many other settings, and their stock of personal experience is considered to be valuable. However, there are no weather experts whose specific advice is sought, nor are there ritual specialists who conduct rain-making ceremonies as there are in some other parts of Africa. Although there are certain individuals who are believed to have special powers to block rains through supernatural means, they are generally feared and avoided by average farmers. These individuals are said to be mostly consulted by ill-intentioned individuals for destructive purposes. Because such practices are strongly condemned by both Christianity and Islam and contradict cherished ideals of modernity and development, people are very reluctant to discuss them.

\subsection{Spatial and temporal scales}

The four identified components offer farmers information at different spatial and temporal scales. The signs offer a lead time of a few weeks, longer than the modern weather forecasts. The other components give lead times that vary from a few weeks to a few days or, in the case of heavy clouds and thunder, a few hours. The climatology draws on decades of lived experience, stretching back to the stories that older people had heard when they were young, and the names of the seasons may be much older. Some components provide forecasts for the immediate vicinity of the local villages and its lands within a few kilometers, while other information draws on more distant areas. This long temporal depth leads people to expect that the patterns will continue into the future, and hence to be attuned to notice shifts in these 
patterns, associated with climate change. For example, during a farmer meeting, a woman made a comment that triggered a discussion about changing seasonal patterns and their causes:

Woman 1.

"What do you think has brought about these weather changes? Formerly, the rains used to start in February [and now they are only beginning in March]"

Woman 2.

Woman 1.

Woman 2.

Woman 3.

"The cutting of trees [may be the cause of this change]."

"By now we should have been receiving intensive rains."

"You have cut down all the trees thinking about what?"

"And we were told [by government officials] that wherever you cut [trees], you plant [new trees]."

Woman 2.

"And something else, the forests where we now have our gardens would be the ones to bring about the rain. But we cut them down and we cultivate there."

Woman 4.

"Because we no longer have anywhere to cultivate before cutting trees."

Woman 5 .

"And we do not replace the ones we cut."

Women [as a group].

Woman 3.

"Yes."

"Will you put a forest in a garden? You only plant a few trees."

Another temporal feature of indigenous climate knowledge is its nature as an ongoing process. Farmers' decisions are often patterned upon an iterative, improvisational sequence of strategic adjustments rather than upon a discrete pre-established farm plan. These adaptive responses are informed by a knowledge that is ingrained in localized practice rather than in technical know-how (Richards 1993; Batterbury 1996). In other words, farmers do not formulate a strategy for the growing season, based on observations they make at one particular time, and then proceed to implement it. Rather, they get their bearings by "sensing" the environment during the weeks that lead up to the onset of the rains and continue to do so until the viable planting time is over, in a process that relies on immediate perceptions and cumulative experience (Orlove and Kabugo 2005). Although they may make initial plans on the basis of the forecast, choosing dates to clear fallow fields of brush, to prepare cleared fields, and to plant, they continue to monitor the season, prepared to make changes as the season unfolds and conditions shift. For example, they might switch to a shorter cycle crops if the rains start later than expected, or if a dry spell follows planting and forces farmers to replant when the rains pick up again. As one woman stated, "[Before the first rainy season started,] I expected rain, which usually comes in March. When it drizzled a few times in March, I thought the season had started and I went ahead and planted, but there was a dry spell and the crops all dried up. The rains came back at the end of April. We planted again because the first crops that we planted completely died."

The fact that farmers monitor seasons on an ongoing basis, rather than relying on a single reading of indicators once and for all, leads them to be very attentive to any possible clue, particularly in the weeks leading up to the onset of the rains. An individual might notice something - a bird's call, a flash of lightning, an overheard comment at a market - that could give them an idea of when the rains may start. This 
sort of watchfulness articulates with the social nature of indigenous knowledge. As people share their observations with others, they may appreciate their significance or understand them differently than when they first noted them. This system thus encourages people to seek and register details that they might share with others later.

\subsection{Multiplicity and integration of information}

The indigenous system includes a number of different, interrelated components. The historical patterns serve as a template that allows farmers to form expectations for a coming season. The signs, the weather observations and the regional information suggest the variations that may alter these normative expectations for a particular season. Local people recognize this multiplicity of components since they distinguish signs or obubonero as a component that is different from the knowledge of climatology that is based on long-term experience, from the immediate visible and audible observation of nearby rainstorms, and from the news of weather events throughout the region gathered from travelers, the radio or conversations on mobile phones.

The people integrate the different sources of information, and at times comment on the difficulty of such integration. They note that each source of information provides probabilities rather than certainty of rain, and therefore they seek to know more. However, different sources do not always point in the same direction, creating possible discrepancy or confusion. One man described his reaction to such circumstances as follows: "I expected the season to do well, because we had some rain in early March [when the rains most often begin]. But usually when it is about to rain here, the wind which is blowing from one direction in February changes direction and blows from the other side. But that month, the wind did not change, so I started worrying. It remained like that till the second week of March. That is when it changed direction, and a week after we got more rain. Sometimes the rains come in March, but, sometimes they don't, and we receive the rains in April, or May. And the rain may go on only for one month and then disappear." Another farmer reported surprise rather than worry at such incongruity. A widowed schoolteacher in her 40s, she stated "Before the onset I expected a good season. I thought it would rain and crops would come out well. At first I saw dark clouds that looked heavy, as if they were carrying water, but I was surprised to see them move away. I heard that it had rained in Masaka [50 km to the northeast] and in Kakuuto [25 km to the south], but not in this area [and so I thought that it would rain here as well]."

One consequence of this lack of integration is the concern that farmers express when a gap arises between their indigenous knowledge and the actual outcomes, such as when rains fail to come at a time when the various components of knowledge all point towards the onset of rains. In such case, particularly if rains fail, supernatural causes may be suspected. This may lead groups to organize sacrifices to the spirit that dwell in the hillside shrines to ask that they release the rains. People often speculate that traders (whose motives and interests farmers believe to be contrary to their own) had undertaken some ritual action to delay the rains, as the latter would disrupt markets. In extreme cases, people might seek a ritual specialist who could determine whether someone placed a curse on the community and suggest how to undo it.

The following sequence of comments comes from a farmer group meeting in March 2006, a week or two into the rainy season, at a time when there was still some uncertainty about whether the rains would continue. By illustrating how various 
individuals may present different pieces of information to assess the upcoming season and to develop concrete plans of action, the excerpt provides an example of the social nature of indigenous knowledge. The six participants are of similar social position, all being married women of average wealth levels, neither rich nor extremely poor. All are in their 30s, with the exception of Woman 4, who is in her 40s. Women 1, 3 and 5 are members of the Church of Uganda, closely affiliated with the Anglican Church; Woman 4 is a Catholic, and Women 2 and 6 are Muslims, which suggests that there can be convergence among different religious background.

Woman 1. "But, my fellow farmers, if it [the rain] brings hailstones like the ones we got yesterday, then we may get good harvests from whatever we have planted [because we are likely to get strong rains].."

Woman 2. "Indeed."

Woman 3. "The way it has started..."

Woman 2. "If it starts the way it came yesterday."

Woman 3. "When it has winds."

Woman 4. "The winds are strong."

Woman 5. "The bananas fell. [That is, the winds were so strong that they knocked bananas off the trees, and, by implication, woman 1 may be incorrect that good harvests lie ahead.]"

Woman 4. "They need to be pruned when it is still early [in the rainy season]. Prune off the dry leaves, such that by the time strong winds come, they are not heavy."

Woman 6. [who had been silent for some time] "What do you have to say about this? [She murmurs for a moment.] What will happen to the cassava? [That is, it might suffer a specific problem as the bananas did.]"

\subsection{Openness to new sources of information}

We suggest that the openness to a variety of components of knowledge leads the farmers to be willing to integrate new information into their system of forecasting weather and climate. If they relied exclusively on one source, farmers might be less willing to adopt new sources. But they do, considering a variety of sources and evaluating them as each season arrives and unfolds. We have previously mentioned the integration of new elements, such as the flowering of coffee trees-a plant that was introduced into the region-as a forecasting sign, and the adoption of scientific terms for clouds learned in the schools. The readiness of farmers to discuss, assess and use modern scientific forecasts, provided by the Ugandan Department of Meteorology, is another example. In the conversations at group meetings, the farmers reviewed forecasts that they had heard in previous seasons on the radio or from agricultural extension agents, and commented that these usually proved to be accurate but on some occasions were incorrect. They also noted that their indigenous forecasts were generally reliable but sometimes failed to provide accurate predictions.

This attention to multiple sources of information can also help farmers to be more aware of climate change. For example, they may comment when a season, or several seasons, departs from the historical patterns, and they will note when the forecasts based on established components, such as signs and weather observations, are not 
borne out. In reflecting on these deviations from established or expected patterns, they detect shifts that might be associated with climate change.

\section{Conclusions}

\subsection{Parallels with other indigenous knowledge systems}

Several features of this indigenous climate knowledge system reflect characteristics common to local environmental knowledge in other contexts, such as practicality, complexity, and dynamism (Ellen and Harris 2000: 4-5). First, this system has a strong practical emphasis, oriented towards agricultural planning. Individuals select the timing of agricultural activities and the specific crops that they will plant. Second, it draws on multiple components that operate on a variety of spatial, temporal and social scales. It requires the integration of information from these different sources. Third, it exhibits remarkable dynamism, which allows for the incorporation of new elements. Such dynamism is expressed in several ways. For example the knowledge system undergoes constant updating: as a doctor updates a diagnosis as a patient's condition progresses, farmers track the rains closely and revise their assessment of the season. In addition, it is continuously re-examined, as new elements are examined and, if found useful, incorporated, and as existing ones are called into question and discarded.

\subsection{Interface with science}

This knowledge system offers points of connection with climate science on two time scales, those of climate variability and climate change. Firstly, it facilitates communication between indigenous and modern scientific knowledge in the arena of climate variability. This system predisposes farmers to be open to scientific forecasts disseminated by the national meteorological services and from the media since they already accept a variety of components of knowledge and evaluate new elements as they present themselves. As traditional healers can borrow from Western biomedicine, and traditional agricultural practices can be combined with modern agrochemicals and new technologies, so too the farmers' climate knowledge can incorporate the use of scientific forecasts. Climate scientists can benefit from recognizing this openness, since such recognition could allow them to design forecasts that would respond to farmers' priorities and would therefore be more widely used by them (Nyong et al. 2007). Indigenous knowledge can help finetune climate predictions, much as traditional healing systems has provided many pharmaceuticals, techniques, information and ideas that Western biomedicine has adopted. For example, scientists can draw on the farmers' indigenous knowledge of spatial variability in climate patterns for the identification of areas at risk for drought, as their current system rests on a coarse spatial analysis that does not address the risks in drier sub-regions within relatively moist regions. Meteorologists could also capitalize on farmers' interest in regional information by providing more systematic coverage of the spread of the rains across the country in each season. Some of the components of indigenous knowledge identified in this paper-historical 
patterns, weather observations and regional information-correspond to sources of information that meteorologists use. This similarity could be used in explaining to farmers how climate forecasts are produced, thereby enhancing their credibility. It might even be possible to explain that meteorologists rely on observations that are similar to signs in order to convey to farmers the way that scientific forecasters draw on statistical models (e.g. linking ENSO indices with rainfall) to make predictions. Finally, the recognition by meteorologists of the highly social nature of indigenous knowledge could also lead to the development and support of innovative forms of forecast dissemination that center on social interaction and group processing, such as incorporating farmer organizations into information delivery systems.

Secondly, the indigenous knowledge system described here facilitates communication between indigenous and modern scientific knowledge in the arena of climate change. It leads farmers to be attentive to changes on long time scales and to compare present conditions to those in the past. Farmers often commented that the timing of the onset of the rains has become less regular. Since the collective memory of the farmers in the district stretches back decades before the beginning of data collection at the meteorological stations, this information is of value. As researchers on climate change in other regions (Hinkel et al. 2007; Laidler and Ikummaq 2008) have recognized, despite the differences in the criteria used by local farmers and scientists to define seasonal phenomena, there is also significant overlap between them, making indigenous observations potentially useful to climate scientists in tracking change.

Linking these two time scales, we suggest a reconsideration of the role of indigenous people, including the farmers among whom we worked, in climate science. The dominant model of forecast use in the climate applications field is one of dissemination and outreach, which casts climate scientists in an active role as "sources of knowledge" and the farmers in a passive role as "recipients of forecasts". The case presented here suggests that forecast users are also active players in the production and transmission of information. The time depth and fine spatial scale of farmers' observations could provide meteorologists with useful information and in this way support the production of scientific knowledge. A number of features of indigenous knowledge, such as its social nature and the correspondence between some of its components and the sources of modern science, could help national meteorological services to develop new means of communication for their forecast products. The efforts of farmers to seek out climate information on their own and to discuss forecasts in groups deepen their understanding and broaden their use (Marx et al. 2007; Roncoli et al. 2008). The farmers are therefore capable of participating as agents as well as consumers in the broad social system of forecast development and use. In these ways, farmers' indigenous knowledge constitutes a resource of great potential value to agencies that develop and disseminate forecasts.

Acknowledgements We would like to recognize the support of the National Science Foundation in funding this research through grant SES-0345840 to the Center for Research on Environmental Decisions at Columbia University. The Ugandan Department of Meteorology gave crucial support during fieldwork; we would particularly like to thank Paul Isabirye and Milton Waiswa. Dorah Nanteza was an invaluable field assistant. We also thank Dave Krantz, Elvira J. Bomsonne, Kenny Broad, John Chiang, Alessandra Giannini, Donna Green, Mark Grote and two anonymous reviewers for useful comments on the paper. Karen Beardsley used her extensive cartographic knowledge and experience and her familiarity with East Africa to prepare the maps. 
Open Access This article is distributed under the terms of the Creative Commons Attribution Noncommercial License which permits any noncommercial use, distribution, and reproduction in any medium, provided the original author(s) and source are credited.

\section{References}

Agrawal A (1995) Dismantling the divide between indigenous and scientific knowledge. Dev Change 26:413-439

Agrawal A (2002) Indigenous knowledge and the politics of classification. Int Soc Sci J 173:287-297

Antweiler C (1998) Local knowledge and local knowing: an anthropological analysis of contested cultural products in the context of development. Anthropos 93:469-494

Antweiler C (2004) Local knowledge theory and method: an urban model from Indonesia. In: Bicker A, Sillitoe P, Pottier J (eds) Investigating local knowledge: new directions, new approaches. Ashgate, Burlington VT, pp 105-128

Anyah RO, Semazzi FHM (2006) Variability of East African rainfall based on multiyear RegCM3 simulations. Theor Appl Climatol 86(1-4):39-62

Appadurai A (1995) The production of locality. In: Fardon R (ed) Counterworks: managing the diversity of knowledge. Routledge, New York, pp 204-225

Ashby JA (1985) The social ecology of soil erosion. Rural Sociol 50(3):337-96

Atran S (1985) The nature of folk-biological life forms. Am Anthropol 87(2):289-315

Batterbury SPJ (1996) Planners or performers? Reflections on indigenous dryland farming in northern Burkina Faso. Agric Human Values 13 (3):12-22

Berlin B, Breedlove DE, Raven PH (1974) Principles of Tzeltal plant classification. Academic, New York

Brodt SB (2001) A systems perspective on the conservation and erosion of indigenous agricultural knowledge in central India. Hum Ecol 29(1):99-120

Brokensha D, Warren D, Werner O (eds) (1980) Indigenous knowledge systems and development. Univ Press Amer, Waltham, MD

Brosius JP (1999) Analyses and interventions: anthropological engagements with environmentalism. Curr Anthropol 40:277-309

Brush SB, Stabinski D (eds) (1996) Valuing local knowledge: indigenous people and intellectual property rights. Island, Washington DC

Chambers R (1996) Whose reality counts? Putting the first last. Intermediate Technology, London

Cleveland D, Soleri D (2007) Farmer knowledge and scientist knowledge is sustainable agricultural development: ontology, epistemology, and praxis. In: Sillitoe P (ed) Local science vs global science: approaches to indigenous knowledge in international development. Berghahn, New York, pp 209-230

Cruikshank J (2005) Do glaciers listen? University of British Columbia Press, Vancouver

Curran LM, Caniago I, Paoli GD, Astianti D, Kusneti M, Leighton M, Nirarita CE, Haeruman H (1999) Impact of El Niño and logging on canopy tree recruitment in Borneo. Science 286:21842188

DeWalt B (1994) Using indigenous knowledge to improve agriculture and natural resource management. Hum Org 53:540-52

Dove M (2000) The life-cycle of indigenous knowledge, and the case of natural rubber production. In: Ellen R, Parkes P, Bicker A (eds) Indigenous environmental knowledge and its transformations. Harwood, Amsterdam, pp 213-252

Dove M, Smith D, Campos M, Mathews A, Rademacher A, Rhee S, Yoder L (2007) Globalisation and the construction of western and non-western knowledge. In: Sillitoe P (ed) Local science vs global science: approaches to indigenous knowledge in international development. Berghahn, New York, pp 129-154

Ellen R, Harris H (2000) Introduction. In: Ellen R, Parkes P, Bicker A (eds) Indigenous environmental knowledge and its transformations. Harwood, Amsterdam, pp 1-34

Hinkel KM, Jones BM, Eisner WR, Cuomo CJ, Beck RA, Frohn R (2007) Methods to assess natural and anthropogenic thaw lake drainage on the western Arctic coastal plain of northern Alaska. $\mathrm{J}$ Geophys Res 112:F02S16.1-F02S16.1. doi:10.1029/2006JF000584

Hintjens HM (1997) What has God to do with sustainable development? A Sahelian dialogue. World Views: Environ Cult Relig 1:211-230 
Huber T, Pedersen P (1998) Meteorological knowledge and environmental ideas in traditional and modern societies: the case of Tibet. J Royal Anthropol Inst 3:577-598

Hunn E (1982) The utilitarian in folk biological classification. Am Anthropol 84:830-47

Ingold T (2003) Two reflections on indigenous knowledge. In: Sanga G, Ortalli G (eds) Nature knowledge: ethnoscience, cognition, and utility. Berghahn, New York

Kanani PR, Pastakia A (1999) Everything is written in the sky! Participatory meteorological assessment and prediction based on traditional beliefs and indicators in Saurashtra. Eubios J Asian Int Bioeth 9:170-176

Kihupi N, Kingamkono R, Dihenga H, Kingamkono M, Rwamugira W (2003) Integrating indigenous knowledge and climate forecasts in Tanzania. In: Vogel C, O'Brien K (eds) Coping with climate variability: the use of seasonal climate forecasts in Southern Africa. Ashgate, Burlington, VT, pp 155-169

Laidler GJ, Ikummaq T (2008) Human geographies of sea ice: freeze/thaw processes around Igloolik, Nunavut, Canada. Polar Record 44:127-153

Liechti F (2006) Birds: blowin' by the wind? J Ornith 147(2):202-211

Majugu A (2006) Investigation of the scientific basis and reliability of observed local indicators for rainfall onset and climatic variability and trends over the Rakai-Kibanda area. Ugandan Dept Meteorology, Kampala. Unpublished report

Marx S, Weber E, Orlove B, Krantz D, Roncoli C, Phillips J (2007) Communication and mental processes: communicating climate uncertainty to individuals and groups by utilizing experiential and analytic processing. Glob Environ Change 17:47-58

Mauro F, Hardison PD (2000) Traditional knowledge of indigenous and local communities: International debate and policy initiatives. Ecol Applic 10(5):1263-1269

McCorkle C (1989) Towards a knowledge of local knowledge and its importance for agricultural RD\&E. Agric Human Values 4:4-13

McDaniel J, Kennard D, Fuentes A (2005) Smokey the Tapir: traditional fire knowledge and fire prevention campaigns in lowland Bolivia. Soc Nat Resour 18(10):921-931

Mukiibi JK (ed) (2001) Agriculture in Uganda, vol II. Crops. Fountain Publishers, Kampala

Mutiso SK (1997) Indigenous knowledge in drought and famine forecasting in Machakos District, Kenya. In: Adams WM, Slikkerveer LJ (eds) Indigenous knowledge and change in African agriculture. Center for Indigenous Knowledge for Agriculture and Rural Development, Ames IA, pp 67-86

Nazarea VD (1999) A view from a point: ethnoecology as situated knowledge. In: Nazarea VD (ed) Ethnoecology: situated knowledge/located lives. University of Arizona Press, Tucson, pp 3-19

Nazarea VD (2006) Local knowledge and memory in biodiversity conservation. Ann Rev Anthropol 35:317-35

Nyong A, Adesina F, Osman E (2007) The value of indigenous knowledge in climate change mitigation and adaptation strategies in the African Sahel. Mitig Adapt Strategies Glob Chang 12:787-797

Orlove BS, Kabugo M (2005) Signs and sight in southern Uganda: representing perception in ordinary conversation. Etnofoor 23(1):124-141

Orlove BS, Chiang JH, Cane MA (2000) Forecasting Andean rainfall and crop yield from the influence of El Niño on Pleiades visibility. Nature 403:68-71

Orlove BS, Chiang JH, Cane MA (2002) Ethnoclimatology in the Andes: a cross-disciplinary study uncovers the scientific basis for the scheme Andean potato farmers traditionally use to predict the coming rains. Am Scientist 90:428-435

Osunade A (1994) Indigenous climate knowledge and agricultural practice in southwestern. Nigeria Malays J Trop Geogr 25:21-28

Pepin N (1996) Indigenous knowledge concerning weather: the example of Lesotho. Weather 41: 242-248

Posey DA (1984) Ethnoecology as applied anthropology in Amazonian development. Hum Org 43:95-107

Posey DA (1986) Topics and issues in ethnoentomology, with some suggestions for the development of hypothesis generation and testing in ethnobiology. J Ethnobiol 6(1):99-120

Posey DA (1996) Protecting indigenous peoples' rights to biodiversity. Environment 38(8):6-9, $37-45$

Posey DA (2000) Ethnobiology and ethnoecology in the context of national laws and international agreements affecting indigenous and local knowledge, traditional resources and intellectual 
property rights. In: Ellen R, Parkes P, Bicker A (eds) Indigenous environmental knowledge and its transformations. Harwood, Amsterdam, pp 35-54

Purcell TW (1998) Indigenous knowledge and applied anthropology: questions of definition and direction. Hum Org 57:258-272

Rhoades RE, Bebbington A (1995) Farmers who experiment: an untapped resource for agricultural research and development. In: Warren M, Slikkerveer LJ, Brokensha D (eds) Indigenous knowledge systems: the cultural dimension of development. Intermediate Technology, London

Richards P (1993) Cultivation: knowledge or performance? In: Hobart M (ed) An anthropological critique of development: the growth of ignorance. Routledge, New York, pp 61-78

Roncoli C (2006) Ethnographic and participatory approaches to research on farmers' responses to climate predictions. Clim Res 33(1):81-99

Roncoli C, Ingram K, Kirshen P (2002) Reading the rains: local knowledge and rainfall forecasting among farmers of Burkina Faso. Soc Nat Resour 15:411-430

Roncoli C, Jost C, Kirshen P, Hoogenboom G, Sanon M, Ingram K, Wootin M, Somé L, Ouattara L, Sanfo B, Sia C (2008) From accessing to assessing forecasts: an end-to-end study of participatory forecast dissemination in Burkina Faso (West Africa). Clim Change 92:433-460

Sillitoe P (1996) A place against time: land and environment in the Papua New Guinea highlands. Routledge, London

Sillitoe P (1998a) The development of indigenous knowledge: a new applied anthropology. Curr Anthropol 39:223-23

Sillitoe P (1998b) What, know natives? Local knowledge in development. Soc Anthropol 6:203-220

Sillitoe P (2000) Let them eat cake: indigenous knowledge, science, and 'the poorest of the poor'. Anthropol Today 16(6):3-7

Sillitoe P (2006) Introduction: indigenous knowledge in development. Anthropol Action 13(3):1-12

Sillitoe P (2007) Local science vs global science: an overview. In: Sillitoe P (ed) Local science vs global science: approaches to indigenous knowledge in international development. Berghahn, New York, pp 1-22

Thompson J, Scoones I (1994) Challenging the populist perspective: rural people's knowledge, agricultural research and extension practice. Agric Human Values 11:58-76

Thrupp LA (1989) Legalizing local knowledge: from displacement to empowerment for Third World people. Agric Human Values 6:13-24

Vedwan N (2006) Culture, climate and the environment: local knowledge and perception of climate change among apple growers in northwestern India. J Ecol Anthropol 10:5-18

Verlinden A, Seely MK, Hillyer A (2006) Settlement, trees and termites in Central North Namibia: a case of indigenous resource management. J Arid Environ 66(2):307-335

Waddell E (1995) How the Enga cope with frost: responses to climatic perturbations in the Central Highlands of New Guinea. Hum Ecol 3(4):249-273

Warren M, Slikkerveer LJ, Brokensha D (eds) (1995) The cultural dimension of development: indigenous knowledge systems. Intermediate Technology, London 